\title{
Microbial Degradation Products from Biphenyl-related Compounds
}

\author{
Ichiro TAKASE, ${ }^{*}$ Toshio OMORI and Yasuji MinODA \\ Department of Agriculture, Faculty of Agricultural Chemistry, \\ The University of Tokyo, Bunkyo-ku, Tokyo 113, Japan \\ * Central Research Laboratories, Ajinomoto Co., \\ Suzuki-cho, Kawasaki 210, Japan
}

Received September 19, 1985

\begin{abstract}
A soil isolate, strain S93B1, identified as Pseudomonas cruciviae could grow on more than ten biphenyl-related compounds including $p$-chlorobiphenyl.

Biphenyl was converted to benzoic acid and $\gamma$-benzoylbutylic acid. Mono-substituted biphenyl compounds such as $o$-bromobiphenyl, $p$-chlorobiphenyl, $o$-nitrobiphenyl and $m$-nitrobiphenyl were converted to $o$-bromobenzoic acid, $p$-chlorobenzoic acid, $o$-nitrobenzoic acid and $m$-nitrobenzoic acid, respectively. Phenol and 2-phenoxymuconic acid were produced on the degradation of biphenyl ether. The formation of 2-phenoxymuconic acid demonstrated that biphenyl ether was degraded through an ortho cleavage pathway and the formation of $\gamma$-benzoylbutylic acid suggested the degradation of biphenyl through a meta cleavage pathway.
\end{abstract}

Polychlorinated biphenyls (PCB) and DDT are representative chemicals that are environmental pollutants. The biodegradation of DDT and chlorinated biphenyls has been studied by several workers. ${ }^{1 \sim 4)}$ Furukawa $e t$ $a .^{5)}$ investigated the bacterial degradation of PCB in detail. They reported the effect of chlorine substitution on the biodegradability of various PCB isomers, and identified various degradation products including chlorinated benzoic acids as end products. They proposed an oxidative pathway of $\mathrm{PCB}^{6)}$ to chlorobenzoic acid through a meta cleavage, which is similar to the biphenyl metabolism proposed by Catelani et al. ${ }^{(7)}$ Wedemeyer $^{8)}$ reported dechlorination of DDT and proposed a degradation pathway for DDT. Focht and Alexander ${ }^{9)}$ investigated the degradation of DDT using the cometabolism technique. Subba-Rao and Alexander ${ }^{10)}$ discussed pathways for the degradation of biphenylmethane, benzhydrol and benzophenone as analogues of DDT metabolites. Francis et al. ${ }^{11)}$ reported the degradation of 1,1-bis(p-chlorophenyl)ethane, an analogue of DDT, through cometabolism. But the further degradation of $p, p^{\prime}$ - dichlorobenzophenone, a product of DDT degradation, has not been reported yet.

There are a lot of biphenyl-related compounds which have substituent groups on their benzene rings other than chlorine atoms. Although biphenyl-related compounds are well known as environmental pollutants, they are useful compounds as herbicides, medicines, antimicrobial agents, liquid crystals, heat media and so on. It is important to investigate the relation between the degradability and the chemical structure of biphenyl-related compounds since it provides useful information for the chemical synthesis of biodegradable molecules. In this report, the microbial degradation of various biphenyl-related compounds is described.

\section{MATERIALS AND METHODS}

Medium. The medium composition was as follows: $\mathrm{NH}_{4} \mathrm{NO}_{3}, 4.0 \mathrm{~g} ; \mathrm{KH}_{2} \mathrm{PO}_{4}, 1.5 \mathrm{~g} ; \mathrm{Na}_{2} \mathrm{HPO}_{4} \cdot 12 \mathrm{H}_{2} \mathrm{O}, 1.5 \mathrm{~g}$; $\mathrm{MgSO}_{4} \cdot 7 \mathrm{H}_{2} \mathrm{O}, 0.2 \mathrm{~g} ; \mathrm{CaCl}_{2} \cdot 2 \mathrm{H}_{2} \mathrm{O}, 10 \mathrm{mg} ; \mathrm{FeSO}_{4} \cdot 7 \mathrm{H}_{2} \mathrm{O}$, $5 \mathrm{mg}$; yeast extract, $0.5 \mathrm{~g}$; and deionized water to make 1 liter. The initial $\mathrm{pH}$ was adjusted to $7.0 \sim 7.2$. Biphenylrelated compounds, $0.2 \sim 0.5 \%(\mathrm{wt} / \mathrm{v})$, were added as the sole sources of carbon to the liquid medium. 
The biphenyl-related compounds were sprinkled onto the plate and agar slant media directly.

Microorganisms. Strain S93B1, capable of utilizing biphenylmethane, was selected from stock cultures in our laboratory.

Cultivation. (1) Enrichment culture and isolation of bacteria capable of growing on biphenyl-related compounds: Five $\mathrm{ml}$ of medium in a test tube $(18 \mathrm{~mm} \times 165 \mathrm{~mm})$ containing about $0.5 \mathrm{~g}$ of soil was incubated on a reciprocal shaker for $7 \sim 10$ days at $30^{\circ} \mathrm{C}$. Three loopfuls of the culture broth was transferred to fresh medium for the secondary enrichment culture. Bacteria were isolated and purified after the secondary enrichment culture.

(2) Measurement of bacterial growth: Bacteria inoculated from an agar slant were incubated with various biphenyl-related compounds in $100 \mathrm{ml}$ of medium for $12 \sim 17$ days at $30^{\circ} \mathrm{C}$, and the growth was determined as the optical density.

(3) Cultivation for isolation of degradation products: One liter of medium in a 5 liter Erlenmeyer flask or 20 liters of medium in a 30 liter jar fermentor with an air flow rate of $1 \mathrm{vvm}$ was incubated for $2 \sim 6$ days at $30^{\circ} \mathrm{C}$.

Cell suspension. Bacteria cultivated in the nutrient broth at $30^{\circ} \mathrm{C}$ were collected by centrifugation, and suspended in $0.1 \mathrm{M}$ phosphate buffer $(\mathrm{pH} 7.0)$ after washing twice with the same buffer. A cell suspension of strain S93B1 in phosphate buffer was incubated with $0.05 \% p, p^{\prime}-$ dichlorobenzophenone for 2 days at $30^{\circ} \mathrm{C}$.
Chemicals. $p$-Chlorobiphenyl, $m$-nitrobiphenyl and $p, p^{\prime}$ dichlorobenzophenone were obtained from Aldrich Chemical Co., Inc. Other compounds were obtained from Tokyo Chemical Industry Co., Ltd.

Analytical methods. Silica gel $\mathrm{GF}_{254}$ (E. Merck A G.) on glass plates was used for thin-layer chromatography (TLC). TLC was developed with a solvent system of benzene-dioxane-acetic acid $(90: 25: 4)$. The melting point was determined with a Nagle hot plate microscope. Infra red (IR) spectra were obtained on nujol with a Japan Spectroscopic Co. IR spectrophotometer, model IR-S. Mass spectra were obtained with a Hitachi mass spectrometer, model RMU-6, with a direct probe inlet system. Nuclear magnetic resonance (NMR) spectra were obtained with a Japan Electron Optics Laboratories NMR apparatus, model JNM-MH-100. Gas chromatography was carried out with a Hitachi gas chromatograph $\mathrm{K}-063$, equipped with a flame ionization detector and a $200 \mathrm{~cm}$ by $0.3 \mathrm{~cm}$ stainless steel column packed with Carbowax $20 \mathrm{M}$ on Gas-Chrom $\mathrm{P}$. The temperature of the column was programmed from $50^{\circ} \mathrm{C}$ to $220^{\circ} \mathrm{C}$ at a rate of $10^{\circ} \mathrm{C} / \mathrm{min}$. The helium gas flow rate was $50 \mathrm{ml} / \mathrm{min}$. Gas chromatograph-mass spectrometry (GC-MS) was carried out with a Hitachi mass spectrometer RMU-6 coupled to a Hitachi gas chromatograph K-063.

\section{RESULTS}

(1) Substrate specificity of strain S93BI

As shown in Table I, strain S93B1 could

Table I. The Growth of Strain S93B1 on Various BIPHENYL-RELATED COMPOUNDS

\begin{tabular}{|c|c|c|c|}
\hline Substrates & Growth & Substrates & Growth \\
\hline Biphenyl & + & 1,1,1-Trichloro-2,2-bis(p-chlorophenyl)- & \\
\hline p-Hydroxybiphenyl & + & ethane (DDT) & - \\
\hline$o$-Hydroxybiphenyl & - & Benzophenone & + \\
\hline$p$-Chlorobiphenyl & + & $p$-Chlorobenzophenone & + \\
\hline$o$-Bromobiphenyl & ++ & $p, p^{\prime}$-Dichlorobenzophenone & - \\
\hline$o$-Nitrobiphenyl & ++ & $p, o^{\prime}$-Dichlorobenzophenone & - \\
\hline$m$-Nitrobiphenyl & + & 5-Chloro-2-hydroxybenzophenone & - \\
\hline$o$-Aminobiphenyl & + & 5-Chloro-2-aminobenzophenone & - \\
\hline 3-Chloro-4-hydroxybiphenyl & - & Biphenylethane & ++ \\
\hline Biphenylmethane & ++ & 1-Hydroxy-1,2-biphenylethane & ++ \\
\hline Benzhydrol & - & meso-1,2-Dibromo-1,2-biphenylethane & - \\
\hline Benzhydryl bromide & + & trans-Stilbene & + \\
\hline Benzhydryl chloride & - & cis-Stilbene & + \\
\hline$\alpha, \alpha$-Dichlorobiphenylmethane & - & Biphenyl ether & ++ \\
\hline 1,1-Biphenylethanol & + & $p$-Bromobiphenyl ether & - \\
\hline p-Hydroxybiphenylmethane & - & $p, p^{\prime}$-Dibromobiphenyl ether & - \\
\hline 5-Chloro-2-hydroxybiphenylmethane & - & $m$-Chlorobiphenylamine & + \\
\hline 5,5'-Dichloro-2,2'-dihydroxy- & & Dichlorinated PCB & ++ \\
\hline biphenylmethane & - & Trichlorinated PCB & + \\
\hline
\end{tabular}


Table II. Taxonomical Properties of Strain S93B1

\begin{tabular}{|c|c|c|c|}
\hline \multicolumn{2}{|l|}{ Morphological characters } & \multicolumn{2}{|l|}{ Production of: } \\
\hline Form & Rods & Nitrite Nutrient & Negative \\
\hline \multirow{2}{*}{ Size } & 0.3 to 0.5 & Succinate & Positive \\
\hline & by 1.2 to 2.0 & Indol & Negative \\
\hline Motility & Motile & Acetylmethyl carbinol & Negative \\
\hline Flagellation & Polar & Hydrogen sulfide Agar & Negative \\
\hline Gram-stain & Negative & Paper & Positive \\
\hline Acid-fastness & NT & Oxidase & Positive \\
\hline \multicolumn{2}{|l|}{ Cultural characters } & Agar & Positive \\
\hline \multicolumn{2}{|l|}{ Nutrient agar colonies } & Catalase & Positive \\
\hline Form & Circular & Urease & Positive \\
\hline Surface & Smooth & Hydrolysis of: & \\
\hline Edge & Entire & Starch & Negative \\
\hline Elevation & Convex to raised & Casein & Negative \\
\hline Color & Primrose to straw & DNA & Negative \\
\hline Lustre & Glistening & Cellulose strip & Negative \\
\hline Optical & Transparent & Utilization of: & \\
\hline Growth & Moderate & Citrate Koser & Positive \\
\hline \multicolumn{2}{|l|}{ Glutamate agar colonies } & Christensen & Positive \\
\hline Form & Circular & Succinate & Positive \\
\hline Surface & Smooth & $p$-OH-benzoate & Weakly positive \\
\hline Edge & Entire & Naphthalene & Negative \\
\hline Elevation & Convex to raised & $m$-Cresol & Strongly positive \\
\hline Color & Straw & Phenol & Negative \\
\hline Lustre & Glistening & Ammonium salts & Positive \\
\hline Optical & Transparent & Acid from: & \\
\hline Growth & Moderate & L-Arabinose & - \\
\hline \multicolumn{2}{|l|}{ Nutrient agar slant } & D-Xylose & - \\
\hline Form & Filiform & D-Glucose O & - \\
\hline Lustre & Glistening & $\mathrm{F}$ & - \\
\hline Color & Straw & D-Mannose & - \\
\hline Growth & Abundant & D-Fructose & - \\
\hline Consistency & Butyraceous & D-Galactose & - \\
\hline Medium & Unchanged & Maltose & - \\
\hline \multicolumn{2}{|l|}{ Nutrient broth } & Saccharose & - \\
\hline Surface growth & Ring & Lactose & - \\
\hline Clouding & Turbid & Trehalose & - \\
\hline Sediment & Scanty & Sorbitol & - \\
\hline \multicolumn{2}{|l|}{ Action on Litmus milk } & Mannitol & - \\
\hline $\mathrm{pH}$ & Alkaline & Inositol & - \\
\hline Liquefaction & Unchanged & Glycerol & - \\
\hline \multicolumn{2}{|l|}{ Action on B.C.P. milk } & Starch & - \\
\hline $\mathrm{pH}$ & Alkaline & Reducing substance from & \\
\hline Liquefaction & Unchanged & gluconate & Negative \\
\hline \multicolumn{2}{|l|}{ Production of water soluble } & \multicolumn{2}{|c|}{ Max. conc. of $\mathrm{NaCl}$ on growth NT } \\
\hline Pigment & Not produced & Relation to & \\
\hline \multicolumn{2}{|l|}{ Gelatin stab } & Free oxygen & Aerobic \\
\hline Growth & Moderate & $\mathrm{pH}$ & 4 to 9 \\
\hline Liquefaction & Unchanged & Temp. Max. & $42^{\circ} \mathrm{C}$ \\
\hline \multicolumn{2}{|l|}{ Gelatin agar plate } & Opt. & 25 to $40^{\circ} \mathrm{C}$ \\
\hline Growth & Moderate & Dibasic amino acid in & \\
\hline Liquefaction & Unchanged & the cell wall & NT \\
\hline \multicolumn{4}{|l|}{ Tyrosine agar plate } \\
\hline Growth & Moderate & \multirow{3}{*}{$\begin{array}{l}\text { Percent guanine plus } \\
\text { cytosine of the DNA }\end{array}$} & \\
\hline Decomposition & Strongly positive & & NT \\
\hline Pigment & Pale brown & & \\
\hline \multicolumn{4}{|l|}{ Physiological characters } \\
\hline Nitrate respiration & Positive & & \\
\hline
\end{tabular}


grown on 18 compounds as the sole sources of carbon among 36 biphenyl-related compounds tested.

\section{(2) Taxonomical study on strain $S 93 B 1$}

Strain S93B1 is a gram-negative rod, and has a polar flagellum. Gelatin was not liquefied and nitrates were not produced from nitrites. According to Bergey's Manual of Determinative Bacteriology 7th edition, it was identified as Pseudomonas cruciviae. The morphological, physiological and cultural characteristics of strain S93B1 are presented in Table II.

\section{(3) Isolation and identification of the deg-} radation products

Strain S93B1 could grow on $o$-bromobiphenyl, $\quad p$-chlorobiphenyl, $o$-nitrobiphenyl, $m$-nitrobiphenyl, biphenyl, $p$-chlorobenzophenone and biphenyl ether as the sole sources of carbon. The degradation products in the respective culture broths were investigated (Fig. 1).

\section{(a) Product from o-bromobiphenyl}

The ethylacetate extract of the acidified supernatant of the $o$-bromobiphenyl culture broth was concentrated. The concentrate was placed on a silica gel (Mallinckrodt Chemical Works, Powder silicic acid AR) column, and eluted by stepwise gradient elution with solvent systems of hexane-benzene and benzene-ethylacetate. Fifty-three mg of white crystals was obtained from 1 liter of culture broth, and the IR spectrum was identical to that of authentic $o$-bromobenzoic acid.

(b) Product from p-chlorobiphenyl

The acidic products were extracted with ethyl ether from $100 \mathrm{ml}$ of the $p$-chlorobiphenyl culture broth and condensed. About $100 \mathrm{mg}$ of white crystals was obtained on recrystallization from ethyl ether. The IR spectrum was identical to that of authentic $p$ chlorobenzoic acid.

(c) Product from o-nitrobiphenyl

Two hundred and eighty $\mathrm{mg}$ of acidic products were extracted from 1 liter of the $o$ nitrobiphenyl culture broth with ethyl-acetate. The major product was scraped off from the
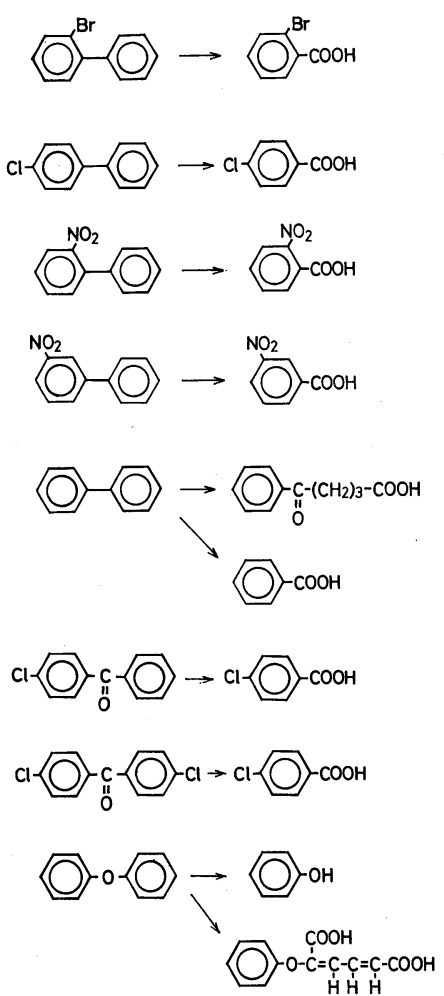

FIG. 1. The Isolated Degradation Products from Biphenyl-related Compounds.

silica gel plate and recrystallized in ethyl ether. The IR spectrum of the crystal was identical to that of authentic $o$-nitrobenzoic acid.

(d) Product from m-nitrobiphenyl

The degradation product from $m$ nitrobiphenyl was purified in the same way as for $o$-nitrobiphenyl. The IR spectrum of the crystal was identical to that of authentic $m$ nitrobenzoic acid.

(e) Products from biphenyl

The biphenyl culture broth was acidified and extracted with ethyl ether. The major product, scraped off from the TLC plate, showed an identical IR spectrum to that of authentic $\gamma$ benzoyl butylic acid. The methyl ester of a minor product showed an identical mass spectrum and retention time on gas chromatograph to those of methylbenzoate.

The other bacterial strains, S540 and S591, grown on biphenyl as the sole source of carbon produced $\gamma$-benzoylbutylic acid. 


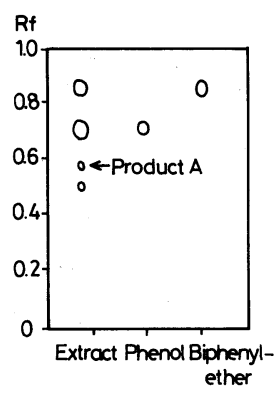

FIG. 2. TLC of the Degradation Products from Biphenyl Ether.

Plate, Merck Kieselgel $\mathrm{GF}_{254}$; solvent, benzene-dioxaneacetic acid $(90: 25: 4)$.

\section{(f) Product from p-chlorobenzophenone}

The acidic products were extracted with ethyl ether from the acidified supernatant of the $p$-chlorobenzophenone culture broth and then recrystallized from ethyl ether. The main product, scraped off from the silica gel plate, showed an identical IR spectrum to that of authentic $p$-chlorobenzoic acid.

(g) Product from $p, p^{\prime}$ dichlorobenzophenone

The product was extracted with ethyl ether from the acidified supernatant of the cell suspension. The product was scraped off from the TLC plate, and the mass spectrum showed a molecular ion peak at $m / z 156$, and the intensity of the parent +2 peak (about $33 \%$ ) strongly indicated the presence of a single chlorine atom in the molecule. Other isotopic peaks were observed at $m / z 139(\mathrm{M}-\mathrm{OH})$ and $m / z 141, m / z 111(\mathrm{M}-\mathrm{COOH})$ and $m / z 113$ in a 3:1 ratio. The compound was identified as chlorobenzoic acid from these results. The $R f$ value on silica gel TLC of the product was the same as that of authentic $p$-chlorobenzoic acid.

\section{(h) Products from biphenyl ether}

Silica gel TLC of the ethyl ether extract of the biphenyl ether culture broth is shown in Fig. 2. The IR spectrum of the ethyl ether extract of the weak acidic fraction was identical to that of authentic phenol. Product A in Fig. 2 was purified by crystallization with a solvent system of ethylacetate-hexane. The crystal melted at $174 \sim 175^{\circ} \mathrm{C}$. Elementary analysis showed; $\mathrm{C}: \mathrm{H}=11.6: 10.0$. The maximum UV absorbance was UV $\lambda_{\max }^{\text {EtOH }} \mathrm{nm}$

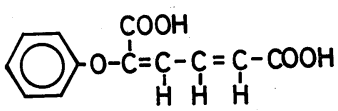

FIG. 3. 2-Phenoxymuconic Acid.

(c): 290 (24,000). A shift of the UV absorbance was not observed under alkaline conditions. The IR, NMR and mass spectra showed the following absorptions and signals. $\mathrm{IR}_{\max }^{\mathrm{Nujol}}$ $\mathrm{cm}^{-1}$ : $1690(\mathrm{C}=\mathrm{O}), 1600(\mathrm{C}=\mathrm{C}), 1420(\mathrm{C}-\mathrm{H})$, $1200 \sim 1300(\mathrm{OH}$ or $\mathrm{C}-\mathrm{O})$. NMR $\delta_{\mathrm{Me}_{4} \mathrm{Si}}^{\mathrm{CD}_{3} \mathrm{OD}}: 4.8$ (singlet $\mathrm{OH}), \quad 5.7 \quad(1 \mathrm{H}$ doublet $\mathrm{CH}-\mathrm{CH}$ conjugated system), $6.9 \sim 7.7(7 \mathrm{H}$ aromatic proton and/or conjugated sytem). MS $m / z: 234$ $\left(\mathrm{M}^{+}\right), 216\left(\mathrm{M}-\mathrm{H}_{2} \mathrm{O}\right), 189(\mathrm{M}-\mathrm{COOH}), 77$ $\left(\mathrm{C}_{6} \mathrm{H}_{5}\right)$. The NMR spectrum of methyl esterified product $\mathrm{A}$ was as follows, NMR $\delta_{\mathrm{Me}_{4} \mathrm{Si}}^{\mathrm{CD}_{3} \mathrm{OD}}: 3.6\left(3 \mathrm{H}\right.$ singlet $\left.\mathrm{CH}_{3}\right), 3.8(3 \mathrm{H}$ singlet $\left.\mathrm{CH}_{3}\right), 5.7(1 \mathrm{H}$ doublet $\mathrm{CH}), 6.9 \sim 7.7(7 \mathrm{H}$ aromatic and/or conjugated protons). Product A was stable on acid hydrolysis (a solution of $40 \mathrm{mg}$ of product $\mathrm{A}$ and $2 \mathrm{ml}$ of $2 \mathrm{~N} \mathrm{HCl}$ in $2 \mathrm{ml}$ methanol was heated at $100^{\circ} \mathrm{C}$ for $3 \mathrm{hr}$ ) but unstable on alkaline hydrolysis (a solution of $40 \mathrm{mg}$ of product $\mathrm{A}$ and $2 \mathrm{ml}$ of $2 \mathrm{~N} \mathrm{KOH}$ in $2 \mathrm{ml}$ methanol was heated at $95^{\circ} \mathrm{C}$ for $3 \mathrm{hr}$ ). Phenol was produced from product $\mathrm{A}$ on alkaline hydrolysis. The structure of product A was considered to be that of 2-phenoxymuconic acid (Fig. 3) from these results.

\section{DISCUSSION}

Fifty soil samples were used for the isolation of bacteria capable of growing on benzophenone, $p$-chlorobenzophenone, $p, p^{\prime}$-dichlorobenzophenone, $p, o^{\prime}$-dichlorobenzophenone, 5-chloro-2-hydroxybenzophenone, benzhydrylchloride, $\quad \alpha, \alpha$-dichlorobiphenylmethane, 5-chloro-2-hydroxybiphenylmethane and 5,5'dichloro-2,2'-dihydroxybiphenylmethane as the sole sources of carbon. The fact that no bacteria were isolated suggests that these compounds are considerably resistant to microbial degradation in natural environments. Then stock culture collection strains were tested as to their ability to degrade chemicals. One strain, S93B1, identified as Ps. cru- 
civiae, which was originally isolated as a biphenylmethane-utilizing bacterium, could grow on benzophenone and p-chlorobenzophenone. Table I shows the substrate specificity of strain S93B1. The strain did not utilize phenolic compounds such as 5-chloro-2-hydroxybenzophenone, 5-chloro-2-hydroxybiphenylmethane or 5,5'-dichloro-2,2'-dihydroxybiphenylmethane. This indicates that phenol groups are considerably toxic for microbial growth. As shown in Table I, strain S93B1 well utilized 18 compounds as growth substrates. This suggested that the enzymes involved in the degradation of biphenylrelated compounds are the same or similar enzymes with wide substrate specificity ranges. Therefore the reason why bacteria were not screened from soil samples by the enrichment culture technique would be that the soil samples contained organic materials which were easily utilized by the bacteria and which probably repressed the formation of the enzyme responsible for the degradation of aromatic compounds.

The biodegradability of biphenyl-related compounds, as shown in Table I, decreases as the number of substituent groups increases, compounds with substituent groups on both aromatic rings being especially more resistant to biodegradation than those with substituent groups on only one aromatic ring. The same results were reported for the degradation of biphenyls by Furukawa and Matsumura. ${ }^{4}$ Strain S93B1 can utilize a variety of monosubstituted compounds with different substituent groups such as halogens or nitro, at different positions such as para or meta, and with different carbon skeletons such as in the cases of biphenyl, biphenylmethane, biphenyl ether, benzophenone and stilbene. Because of the formation of mono-substituted benzoic acids, mono-substituted biphenyls seem to be degraded through a similar pathway.
As in a previous study, ${ }^{2)} \gamma$-benzoylbutylic acid was produced from biphenyl by strains S93B1, S540 and S591. Strains S540 and S591 were originally isolated as biphenyl-utilizing bacteria. The $\gamma$-benzoylbutylic acid seemed to be formed through reduction and decarboxylation from the meta-cleavage product (2-hydroxy-6-oxo-phenylhexa-2,4-dienoic acid) of 2,3-dihydroxybiphenyl. This suggested the general existence of an unknown reductive step in the metabolic pathway of biphenyl to $\gamma$-benzoylbutylic acid. The production of $\gamma$-benzoylbutylic acid demonstrates that strain S93B1 has a meta cleavage pathway of 2,3-dihydroxybiphenyl. In addition, the formation of 2-phenoxymuconic acid from biphenyl ether also indicated the existence of an ortho cleavage. Thus, strain S93B1 may have two enzyme systems which catalyze meta and ortho cleavage in the degradation of biphenyl-related compounds.

\section{REFERENCES}

1) A. Ahmed and D. D. Focht, Can. J. Microbiol., 19, 47 (1973)

2) T. Ohmori, T. Ikai, Y. Minoda and K. Yamada, Agric. Biol. Chem., 37, 1599 (1978).

3) K. Furukawa, F. Matsumura and K. Tonomura, Agric. Biol. Chem., 42, 543 (1978).

4) K. Furukawa and F. Matsumura, J. Agric. Food Chem., 24, 251 (1976).

5) K. Furukawa, K. Tonomura and A. Kamibayashi, Appl. Environ. Microbiol., 35, 223 (1978).

6) K. Furukawa, K. Tonomura and A. Kamibayashi, Agric. Biol. Chem., 43, 1577 (1979).

7) D. Catelani, A. Colombi, C. Sortini and V. Treccani, Biochem. J., 134, 1063 (1973).

8) G. Wedemeyer, Applied Microbiology, 15, 569 (1967).

9) D. D. Focht and M. Alexander, J. Agric. Food Chem., 19, 20 (1971).

10) R. V. Subba-Rao and M. Alexander, Appl. Environ. Microbiol., 33, 101 (1977).

11) A. J. Francis, R. J. Spanggord, G. I. Ouchi and N. Bohonos, Appl. Environ. Microbiol., 35, 364 (1978). 